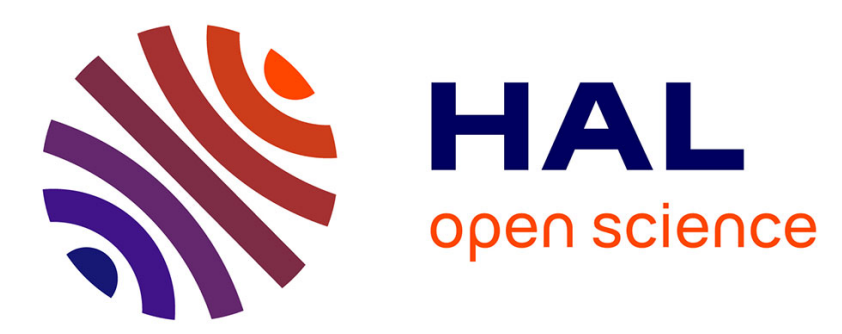

\title{
SPECTROSCOPIE RAMAN COHÉRENTE DANS UN RÉACTEUR CVD
}

\author{
N. Herlin, M. . Lefebvre, M. Péalat, M. Parlier
}

\section{To cite this version:}

N. Herlin, M. . Lefebvre, M. Péalat, M. Parlier. SPECTROSCOPIE RAMAN COHÉRENTE DANS UN RÉACTEUR CVD. Journal de Physique Colloques, 1989, 50 (C5), pp.C5-13-C5-13. 10.1051/jphyscol:1989503 . jpa-00229526

\section{HAL Id: jpa-00229526 https://hal.science/jpa-00229526}

Submitted on 1 Jan 1989

HAL is a multi-disciplinary open access archive for the deposit and dissemination of scientific research documents, whether they are published or not. The documents may come from teaching and research institutions in France or abroad, or from public or private research centers.
L'archive ouverte pluridisciplinaire HAL, est destinée au dépôt et à la diffusion de documents scientifiques de niveau recherche, publiés ou non, émanant des établissements d'enseignement et de recherche français ou étrangers, des laboratoires publics ou privés. 
JOURNAL DE PHYSIQUE

Colloque C5, supplément au $n^{\circ} 5$, Tome 50, mai 1989

SPECTROSCOPIE RAMAN COHÉRENTE DANS UN RÉACTEUR CVD

N. HERLIN, M. LEFEBVRE, M. PEALAT et M. PARLIER

Office National d'Etudes et de Recherches Aerospatiales, BP. 72 , F-92322 Châtillon Cedex, France

(recent news) 